\title{
Impact of prechemotherapy preparation on knowledge, coping attitude and satisfaction among newly diagnosed patients with cancer
}

\author{
Samira E. Aboalizm, Hanaa E. El-Sayad* \\ Medical Surgical Nursing Department, Faculty of Nursing, Menoufia University, Egypt
}

Received: January 14, 2019

DOI: $10.5430 /$ cns.v7n2p95
Accepted: March 28, 2019

Online Published: April 14, 2019

\begin{abstract}
Objective: Cancer's patients receiving chemotherapy need information about the treatments and self-care that must practice in order to prevent serious complications. Purpose of the study: To determine the impact of prechemotherapy preparation on knowledge, coping attitude and satisfaction among newly diagnosed patients with cancer.

Methods: Quasi experimental research design was used. The study was conducted at outpatient's chemotherapy clinic and at word of the Oncology Menoufia University Hospital, Shebin El-Kom, Egypt. A convenience sample of 100 adult patients of both sexes who were diagnosed with cancer in the Oncology outpatient clinic and would receive first time chemotherapy treatment were enrolled in this study. Three tools were used. Tool I: Chemotherapy Patients needs assessment: structured interviewing scheduled questionnaire: The tool consisted of the following 2 parts. Part I: Sociodemographic and clinical data, Part II: Pre Chemotherapy Knowledge Assessment Sheet. Tool II: 16 attributes of cancer therapy satisfaction questionnaire (CTSQ). Tool III: Cancer Coping Questionnaire (CCQ) 21 Items Versions.

Results: The study group had better knowledge, coping and satisfaction post intervention than control group. There was statistically considerable differences between study and control group concerning the mean total score of satisfaction and coping ( $p$ value $<.001)$. There were significant positive correlation total score of cancer coping and mean score of cancer therapy satisfaction $p$ value $<.001$.

Conclusions: Prechemotherapy preparation to cancer patients improved patient's knowledge, satisfaction and coping. Recommendation: Prechemotherapy education should be considered a part of routine nursing care performed for all newly diagnosed patients with cancer who would receive chemotherapy for first time.
\end{abstract}

Key Words: Chemotherapy preparation, Knowledge, Coping attitude, Satisfaction

\section{INTRODUCTION}

Cancer is the second leading cause of death worldwide after cardiovascular disease. Chemotherapy is one of major important element of cancer management with the rule of destroying the actively dividing cancer cells through the use of anticancer drugs. As a consequence of this, other cells, that are actively divided in the body such as cells in bone marrow, cells in the lining of the mouth, and intestines beside hair follicles would also be affected which cause greater side effects. ${ }^{[1]}$

\footnotetext{
*Correspondence: Hanaa E. El-Sayad; Email: hanaa.elsayyad@yahoo.com; Address: Medical Surgical Nursing Department, Faculty of Nursing, Menoufia University, Egypt.
} 
Patients who receive chemotherapy often suffer from not only physical side effects as nausea, vomiting, stomititis, fatigue, hair loss, neutropenia but also psychological side effects include treatment-related anxiety, needle phobias and concerns about treatment extent. Moreover a cancer diagnosis makes patient feel worried, sad, confused or angry. Specific report common physical and psychosocial problems and rates of psychiatric and psychosocial morbidity are classically elevated. $^{[2]}$

More than $50 \%$ of newly diagnosed cancer patients are expected to experience physical side-effects including fatigue, insomnia, nausea, weight loss, mucositis, alopichia and pain as a consequence of their cancer treatment. There is a variation in the intensity of these side-effects between patients receiving the same chemotherapeutic agent. The manner of explaining information about side effects is provided to the patients may affect patient expectations. Patient who receive little or incomplete information may experience more sever side-effects. ${ }^{[3]}$

Various cancer patients often do not understand and remember greatly of the information they receive within a medical consultation and state dissatisfaction with the amount and feature of information given to them about their disease and treatment. As a result of this, these patients express poorly compliance with treatment and less coping with their disease. Several studies suggested combining both verbal and written information to increase patients' knowledge about chemotherapy side effects, improve their coping and satisfaction. It has been illustrated that prechemotherapy information should meet the clients' needs, be simple and easy to understand to be effective. ${ }^{[4,5]}$

The high rate of patient psychological grief and the need for self-care information recommend that existing prechemotherapy preparation is suboptimal. An early study presented that information about side-effects places a greater challenge to oncology nurses to improve patient self-care activity and satisfaction about disease. ${ }^{[6]}$

Prechemotherapy patient training is one type of psychosocial involvement. Educating patients about their possible side effects and methods to deal with them can reduces anxiety, improves coping mechanisms, reduces decisional conflicts, encourages patient independence, and develops the patient knowledge. Patients who understand their disease and its treatment also comply better with therapy which translated into better outcomes. It is essential that patients cured with chemotherapy be educated about what to expect from their chemotherapy routine and proper use of their medications. Insufficient knowledge about their chemotherapy management and how to deal with related adverse effects could lead to increased hospital admissions, increased morbidity, and decreased quality of life for the patient. ${ }^{[7]}$

Providing preparatory chemotherapy information can improve cancer patient outcome especially with respect to patients' knowledge and satisfaction. Face to face prechemotherapy teaching is highly acceptable by patients and was found to increase self-efficacy and reduce supportive care needs added to this it can reduce their pretreatment anxiety and enhance their confidence in coping with treatment. ${ }^{[3]}$

In the recent years, the role of the nurse has been actively assimilated into the primary health care system in revealing medical care. Nurse directed medical therapy adherence clinic and counseling have shown great impact on patient compliance to the medicine prescribed. The oncology nurse plays an important role in patient's awareness and education. She should clarify what chemotherapy treatment is and how it works in common terms, and then gives the patient more specific information about the prescribed drugs, their actions and side-effects. Patients are also told how to cope with any side-effects which can include sickness, diarrhea, sore mouth or high temperature. ${ }^{[6]}$

Furthermore, the oncology nurses not only responsible for handling chemotherapy treatments to cancer patients, but also have the responsibility to recommend the patient information and instruction on the chemotherapy process, as well as provide them medications and preparations for any potential chemotherapy side effects and assists patients in effectively managing these side effects at home. Moreover, they provide educational resources and information on helping patient find methods to cope with the stress of a cancer diagnosis, providing guidance and support to patient living with cancer. ${ }^{[8]}$

Several studies have been conducted to determine impact of prechemotherapy education on improvement of patients' anxiety and coping. Precheomotherapy education has resulted in increase patients' knowledge about chemotherapy side effects but this research is varied. Research suggests that adequate patients preparation before chemotherapy can improve their coping and satisfaction. ${ }^{[9,10]}$

\subsection{Significance of the study}

National Cancer Registry Program ${ }^{[11]}$ reported that around 100,000 Egyptians are diagnosed with cancer annually and the incidents are 166 for every 10,000 people in Egypt. Moreover statistical records of Menoufia University Hospital illustrated that 1,450 patients were diagnosed with cancer during the year 2015. ${ }^{[12]}$ Cancer is a collection of further than 200 disease characterized by wild and unfettered growth of cells. It is a major health problem that occurs in people 
of all ethnicities. ${ }^{[13]}$ Every year at least 200,000 people die worldwide from cancer related to their workplace. Clinical studies have found that traditional minority cancer patients see less patient-centered preparation and receive less biomedical information before the clinical treatment. So understand and use health information, recognize instructions, participate in medical decisions, maintain healthy lifestyle practices can decrease anxiety and apprehension among early cancer chemotherapy treatment. Assessment of the patient's understanding of the disease and recommended treatment is important in improving patient satisfaction and coping behavior. Thorough patient preparation improves submission with treatment programs and may influence treatment outcomes as well. ${ }^{[4]}$

\subsection{Purpose of the study}

The purpose of present study was to determine the impact of chemotherapy preparation on knowledge, coping attitude and satisfaction among newly diagnosed patients with cancer.

\section{Research hypotheses:}

(1) The patients who had received preparation before chemotherapy administration (study group) had better knowledge score than those who had not (control group).

(2) Coping attitude of patients who had received preparation before chemotherapy administration (study group) would be higher than coping attitude of those who had not (control group).

(3) The satisfaction score of patients who had received preparation before chemotherapy (study group) would be higher than those who had not (control group).

\section{METHOD}

\subsection{Research design}

In order to attain the purpose of study, a quasi experimental research design was utilized.

\subsection{Setting}

The current study was performed at outpatient's chemotherapy clinic and at ward of the Oncology Menoufia University Hospitals, Shebin El-Kom, Egypt.

\subsection{Subjects}

A convenience sample of 100 adult patients of both sexes who were diagnosed with cancer in the Oncology outpatient clinic and would receive first time chemotherapy treatment were selected. The sample was divided alternatively into two equal groups (50 patients in each group). They were chosen based on the subsequent power analysis.

Published by Sciedu Press

\subsection{Power analysis: Size}

The sample sizing assumes that the estimated effect size is 6 and the standard deviation of outcome variable is 10 . To accomplish $80 \%$ power to detect this difference with a significance level of 0.05 by the equation: $\mathrm{n}=\left[\left(\mathrm{Z}_{\alpha / 2}+\mathrm{Z}_{\beta}\right)^{2} \times\right.$ $\left.2\left(o^{2}\right)^{2}\right] /(\mu 1-\mu 2)^{2}$ it is estimated that 44 subjects per group would be required. By means of a withdrawal/non-evaluable subject rate of $10 \%$ a total of 48 subjects per group, so that the total sample size of 96 subjects would be included in the present study.

\subsection{Inclusion criteria}

Patients were suitable for study participation when they had the subsequent criterion:

- Mature and alert patient

- Both sexes

- Age from 18-60 years

- Newly diagnosed subjects with cancer and would receive chemotherapy for initial occasion

\subsection{Exclusion criteria}

- Had no psychiatric disorders

- Had no problems that affect on the psychological condition

- No Preceding chemotherapy treatment

- No radiotherapy or other treatment modalities

\subsection{Tools}

In order to gather the required information 3 tools were used by the investigators that included:

\subsubsection{Tool I: Chemotherapy patients needs assessment: structured interviewing scheduled questionnaire}

It was produced by the investigators after reviewing of the related studies ${ }^{[4,5]}$ to identify the required care for newly diagnosed cancer patient who would receive chemotherapy and it divided into two parts:

- Part I: Sociodemographic and clinical data: It was consisted of items regarding to patients' age, sex, marital status, educational level, occupation, cancer diagnosis, and history of associated disease.

- Part II: Pre chemotherapy knowledge assessment sheet: This sheet was used to assess patient's knowledge about chemotherapy, it composed of 10 questions: related to definition, aim, routes of administration chemotherapy, how chemotherapy work, duration of chemotherapy treatment, place of receiving chemotherapy, steps of chemotherapy, side effect of giving chemotherapy, how does patient deal with these side effects, and time to contact the physician. 
Scoring system: The answer of every question was scored as following:

(1) Score two mean correct and complet answer

(2) Score one mean correct and incomplete

(3) Score zero mean incorrect answer

The patient's answers were sumed up to calculate the total knowledge score that ranged from 0 to 20 and was categorized into: A score of $12<10(<50 \%)$ denoted poor or unsatisfactory results, a score of $10<15(50 \%-75 \%)$ denoted fair results and a score from 15 to 20 denoted good or satisfactory results.

\subsubsection{Tool II: 16 attributes of cancer therapy satisfaction questionnaire (CTSQ)}

It was developed by Abetz et al. ${ }^{[14]}$ It was used to assess the patient's cancer therapy satisfaction. The CTSQ contains three domains covering 16 items: expectations of therapy (ET) It consisted of five items, feelings about side effects (FSE) It consisted of four items and satisfaction with therapy (SWT) It consisted of seven items.

Scoring system: Every item was scored on a range from one to five (one means never, second means rarely, four means most of time and five means always) with a value of one matching with the worst answer and a value of five representing the best answer. Four items are reverse-coded. Domain score was calculated by the rule: (mean of fulfilled item scores -1$) \times 25$. This results in a domain score ranging from 0 to 100 , with a higher score representing a better result on every domain.

\subsubsection{Tool III: Cancer Coping Ouestionnaire (CCQ) 21 Items Versions}

The basic questions for the CCQ were drived by using the manual for ATP of greer and moorey. ${ }^{[15]}$ CCQ consisted of 41 items of the original questionnaire were decreased to 21 items. The first 4 subscales are resulted from the factor analysis and create the 14 questions and answered by all patients. The last 7 questions are answered by patients who have partners and construct the Interpersonal Scale.

\section{The subscales are labeled}

(1) Total individual scale (Items 1-14).

Subscales: coping (Items 2,6,7,11,12), positive focus (Items 1,9,14), Diversion (Items 3,4,8), Planning (Items 5,10,13).

(2) Interpersonal scale (Items 15-21).

Scoring system: Each questions was scored on a scale from one to four (one means not at all, the second means sometimes, three means often four means very often). This results in a domain score ranging from 0 to 100 , with a higher score (more than 50\%) representing a better coping on each domain.

\subsection{Method of intervention}

\subsubsection{Tools development}

After reviewing literature extensively, ${ }^{[4,5]}$ the first tool of the study was developed by the researchers. The second tool was developed by Abetz et al. ${ }^{[14]}$ The third tool was developed by Moorey and Greer. ${ }^{[15]}$ The content validity of the first tool was tested by a panel of five experts specialized in Medical Surgical Nursing, and Oncology Medicine to ascertain relevance and completeness.

The reliability of all tools was tested by intra class reliability coefficient. It was 1.9 for tool I and 0.80 and Cronbach's alpha above 0.80 for tool II and the internal consistency of tool III was 0.87 and test-retest was 0.90 .

A pilot study was conducted on 10 patients (10\%) to test clarity, feasibility, applicability and relevance of the developed tools and to determine the needed time for collecting data. Modifications were done accordingly and the seven patients were excluded from the final study sample.

\subsubsection{Data collection}

Data collection was extended from the beginning of December 2017 to the end of April 2018. The researchers assessed knowledge and satisfaction and coping level for the studied sample (study and control group) before beginning first dose of chemotherapy. In order to prevent contamination of the data the control group was manipulated firstly. Subjects of the studied groups were interviewed before intervention using the tool I to identify patients' assessment needs pre chemotherapy.

\subsubsection{Implementation phase}

- A colored booklet in simple Arabic language prepared by researchers including a clear explanation about aim of chemotherapy, routes of administration chemotherapy, how chemotherapy work, duration of chemotherapy treatment, steps of giving chemotherapy before treatment, chemotherapy side effects, how does patient deal with these side effects, and time that patients should contact the physician.

- The researchers interacted with all patients whose physician recommended first time chemotherapy for them at outpatient clinic in oncology institute hospital, researchers introduced themselves, clarify the aim of the study to both study and control groups and assess knowledge, satisfaction, coping level for both study and control groups. It took about 45-60 minutes.

- The prechemotherapy schedule education (intervention) divided into 3 sessions. 
- In the first session, the researchers provided teaching regarding chemotherapy through reading the booklet. The researcher supplied every subject of the study group with a booklet included an explanation of chemotherapy regimen (aim of chemotherapy, routes of administration chemotherapy, how chemotherapy work, duration of chemotherapy treatment, steps of giving chemotherapy before treatment, chemotherapy side effects, how does patient deal with these side effects, time that patient should contact the physician). This done immediately after decision of chemotherapy was made in either outpatient clinic or at oncology ward. It took about 45 minutes.

- Second session on the day of the chemotherapy administration (45 minutes before initial administration of chemotherapy) reinforce the teaching about chemotherapy preparation by using booklet. It took place at either outpatient clinic (for some patients) or at hospital word (for other patients).

- Subjects of the control group was received only routine hospital care (measuring vital signs and giving prescribed medication).

- Subjects of the study group was received the prechemotherapy schedule education by the researchers beside routine hospital care.

- Third session performed one month post chemotherapy to assess knowledge, satisfaction and coping behavior of the studied sample.

\subsection{Evaluation of the intervention}

Every subject of the studied sample was assessed before intervention and before initial dose of chemotherapy. Also they were assessed one month post intervention and post chemotherapy administration to evaluate their knowledge, coping behavior and satisfaction using tool I, tool II and tool III.

\subsection{Ethical consideration}

A written permission was obtained from the hospital's director and the head nurse of the oncology department after clearing up the purpose of the study. A written consent to participate in the study was obtained from all participants after explanation of the purpose of the study. They were reassured any obtained information would be confidential and would only be utilized for the study's aim. The investigators emphasized that participation in the study was entirely voluntary and would not affect their care. Also anonymity of subjects was assured through coding data.

\subsection{Statistical analysis}

The collected data were tabulated \& analyzed by SPSS (statistical package for the social science software) statistical package version 20 on IBM compatible computer.

Two types of statistics were done:

(1) Descriptive statistics were expressed as mean and standard deviation $(\bar{X}+\mathrm{SD})$ for quantitative data or number and percentage (No \& \%) for qualitative data.

(2) Analytic statistics

- Pearson Chi-square test $\left(\chi^{2}\right)$ : It is the test of significance used to study association between two qualitative variables.

- Student $t$-test: It is a test of significance used for comparison between two independent groups of normally distributed quantitative variables.

- Mann-Whitney test (non-parametric test): It is a test of significance used for comparison between two groups of not normally distributed quantitative variables.

- Kruskalwallis test (non-parametric test): It is a test of significance used for comparison between more than two groups of not normally distributed quantitative variables.

- Wilcoxon test: It is a test of significance used for comparison between two related groups of not normally distributed quantitative variables.

- Paired sample $t$-test: It is a test of significance used for comparison between two related groups of normally distributed quantitative variables.

- Spearman correlation: It is a test of significance used for quantitative variables that were not normally distributed or when one of the variables is qualitative.

$p$-value at .05 was used to determine significance regarding:

- $p$-value $>.05$ to be statistically insignificant

- $p$-value $\leq .05$ to be statistically significant

- $p$-value $\leq .001$ to be highly statistically significant

\section{Results}

Table 1 shows that the mean age of study and control group was $53.26 \pm 9.0$ and $52.20 \pm 9.38$ years respectively. More than half of study group (60.0\%) and control group (52.0\%) were male. There were no statistical significant differences between both groups (study and control) regarding sociodemographic characteristics.

Table 2 reveals that the majority of both studied groups had poor chemotherapy knowledge total score pre intervention ( $88.0 \%$ and $92.0 \%$ respectively). More than two thirds of the study group $(70.0 \%)$ had good chemotherapy knowledge 
total score and $82.0 \%$ of the control group had poor total chemotherapy knowledge score post intervention. There was statistically significant differences between both groups (study and control) regarding chemotherapy knowledge total score post intervention $(p$ value $<.001)$.

Table 3 presents that more than half of the study group (58.30 \pm 24.61 ) had positive expectation of the therapy compared to $13.20 \pm 13.58$ of the control group post intervention. More than half of the study group $(59.62 \pm 24.06)$ and only 13.62 \pm 13.22 of the control group had positive feeling about side effects post intervention. More than two thirds of the study groups (62.14 \pm 23.13$)$ as compared to $17.35 \pm 16.98$ of the control group were satisfied with therapy post intervention. There was statistically significant differences between study and control group regarding the mean total score of satisfaction $(p$ value $<.001)$.

Table 4 illustrates that the mean total score of cancer cop- ing $58.2 \pm 13.58$ of the study group as compared to $29.6 \pm$ 6.54 of the control group. There was statistically significant differences between study and control group regarding the mean total score of cancer coping ( $p$ value $<.001$ ).

Table 5 reveals that there were significant positive correlations between total score of knowledge \& total score of cancer coping among study group ( $r=0.68$ and $p$ value).

Figure 1 illustrates that mean total score cancer therapy satisfaction $60.2 \pm 23.55$ of the study group as compared to $14.72 \pm 13.10$ of the control group at post intervention.

There were significant positive correlation between total score of knowledge and cancer therapy satisfaction $p=.001$ (see Table 6).

There were significant positive correlation total score of cancer coping and mean score of cancer therapy satisfaction $p$ value $<.001$ (see Table 7).

Table 1. Socio-demographicc characteristics and clinical data of the subjects

\begin{tabular}{|c|c|c|c|c|c|c|}
\hline \multirow{3}{*}{$\begin{array}{l}\text { Socio-demographic } \\
\text { characteristics }\end{array}$} & \multicolumn{4}{|c|}{ Studied groups } & \multirow{3}{*}{$\chi^{2}$} & \multirow{3}{*}{$p$ value } \\
\hline & \multicolumn{2}{|c|}{ Group I (Study) $(\mathrm{n}=\mathbf{5 0})$} & \multicolumn{2}{|c|}{ Group II (Control) $(\mathrm{n}=\mathbf{5 0})$} & & \\
\hline & No. & $\%$ & No. & $\%$ & & \\
\hline \multicolumn{7}{|l|}{ Age (years): } \\
\hline Mean \pm SD & \multicolumn{2}{|l|}{$53.26 \pm 9.0$} & \multicolumn{2}{|l|}{$52.20 \pm 9.38$} & \multirow[t]{2}{*}{0.57} & \multirow[t]{2}{*}{.56} \\
\hline Range & \multicolumn{2}{|l|}{$27.0-60.0$} & \multicolumn{2}{|l|}{$30.0-60.0$} & & \\
\hline \multicolumn{7}{|l|}{ Gender: } \\
\hline Male & 30 & 60.0 & 26 & 52.0 & \multirow[t]{2}{*}{0.64} & \multirow[t]{2}{*}{.42} \\
\hline Female & 20 & 40.0 & 24 & 48.0 & & \\
\hline \multicolumn{7}{|l|}{ Education: } \\
\hline No education & 22 & 44.0 & 19 & 38.0 & \multirow{3}{*}{0.38} & \multirow{3}{*}{.82} \\
\hline Moderate education & 22 & 44.0 & 24 & 48.0 & & \\
\hline High graduate education & 6 & 12.0 & 7 & 14.0 & & \\
\hline \multicolumn{7}{|l|}{ Occupation: } \\
\hline Muscle work & 19 & 38.0 & 17 & 34.3 & \multirow{3}{*}{0.36} & \multirow{3}{*}{.83} \\
\hline Mental work & 7 & 14.0 & 9 & 18.0 & & \\
\hline Not work & 24 & 48.0 & 24 & 48.7 & & \\
\hline \multicolumn{7}{|l|}{ Marital status: } \\
\hline Single & 0 & 0.0 & 0 & 0.0 & \multirow{4}{*}{ NA } & \multirow{4}{*}{ NA } \\
\hline Married & 50 & 100.0 & 50 & 100.0 & & \\
\hline Widower & 0 & 0.0 & 0 & 0.0 & & \\
\hline Divorced & 0 & 0.0 & 0 & 0.0 & & \\
\hline \multicolumn{7}{|l|}{ Residence: } \\
\hline Spouse & 21 & 42.0 & 29 & 58.0 & \multirow[t]{2}{*}{2.56} & \multirow[t]{2}{*}{.11} \\
\hline Family & 29 & 58.0 & 21 & 42.0 & & \\
\hline \multicolumn{7}{|l|}{ Cancer diagnosis: } \\
\hline GIT cancer & 19 & 38.0 & 20 & 40.0 & \multirow{5}{*}{0.35} & \\
\hline Genitourinary cancer & 5 & 10.0 & 5 & 10.0 & & 98 \\
\hline Respiratory cancer & 12 & 24.0 & 12 & 24.0 & & .90 \\
\hline Leukemia & 2 & 4.0 & 0 & 0.0 & & \\
\hline Breast cancer & 12 & 24.0 & 13 & 26.0 & & \\
\hline
\end{tabular}


Table 2. Total chemotherapy knowledge scoreof the subjects

\begin{tabular}{|c|c|c|c|c|c|c|}
\hline \multirow{3}{*}{$\begin{array}{l}\text { Chemotherapy Knowledge } \\
\text { Assessment }\end{array}$} & \multicolumn{4}{|c|}{ Studied groups } & \multirow{3}{*}{ Test of sig. } & \multirow{3}{*}{$p$ value } \\
\hline & \multicolumn{2}{|c|}{ Group I (Study) (n = 50) } & \multicolumn{2}{|c|}{ Group II (Control) $(n=50)$} & & \\
\hline & \multicolumn{2}{|c|}{ Mean \pm SD } & \multicolumn{2}{|c|}{ Mean \pm SD } & & \\
\hline \multicolumn{6}{|l|}{ Total knowledge score: } & \\
\hline Pre & \multicolumn{2}{|c|}{$3.72 \pm 3.07$} & \multicolumn{2}{|c|}{$3.02 \pm 2.69$} & $\mathrm{U}=0.83$ & .40 \\
\hline Post & \multicolumn{2}{|c|}{$16.22 \pm 3.18$} & \multicolumn{2}{|c|}{$4.52 \pm 4.50$} & $\mathrm{U}=7.91$ & $<.001$ \\
\hline Test of sig. & \multicolumn{2}{|c|}{$\mathrm{W}=6.15$} & \multicolumn{2}{|c|}{$\mathrm{W}=3.61$} & & \\
\hline$p$ value & \multicolumn{2}{|c|}{$<.001$} & \multicolumn{2}{|c|}{$<.001$} & & \\
\hline Knowledge score categories pre: & No. & $\%$ & No. & $\%$ & & \\
\hline Poor & 44 & 88.0 & 46 & 92.0 & & \\
\hline Fair & 5 & 10.0 & 4 & 8.0 & 1.15 & .56 \\
\hline Good & 1 & 2.0 & 0 & 0.0 & & \\
\hline \multicolumn{7}{|l|}{ Knowledge score categories post: } \\
\hline Poor & 1 & 2.0 & 41 & 82.0 & \multirow{3}{*}{$\chi^{2}=69.86$} & \multirow{3}{*}{$<.001$} \\
\hline Fair & 14 & 28.0 & 7 & 14.0 & & \\
\hline Good & 35 & 70.0 & 2 & 4.0 & & \\
\hline
\end{tabular}

Table 3. Total score of cancer therapy satisfaction attributes of the subjects

\begin{tabular}{|c|c|c|c|c|}
\hline \multirow{3}{*}{$\begin{array}{l}\text { Attributes of cancer therapy } \\
\text { satisfaction }\end{array}$} & \multicolumn{2}{|c|}{ Studied groups } & \multirow{3}{*}{$\begin{array}{l}\text { Test of sig. } \\
\text { (U) }\end{array}$} & \multirow{3}{*}{$p$ value } \\
\hline & Group I (Study) $(n=50)$ & Group II (Control) $(\mathrm{n}=\mathbf{5 0})$ & & \\
\hline & Mean \pm SD (Range) & Mean \pm SD (Range) & & \\
\hline \multicolumn{5}{|l|}{ Expectations of therapy (ET) } \\
\hline Pre & $25.90 \pm 14.31(0-50)$ & $29.0 \pm 22.45(0-75)$ & 0.007 & .99 \\
\hline Post & $58.30 \pm 24.61(25-100)$ & $13.20 \pm 13.58(0-50)$ & 7.91 & $<.001$ \\
\hline Test of sig. & $\mathrm{W}=6.0$ & $\mathrm{~W}=4.50$ & & \\
\hline$p$ value & $<.001$ & $<.001$ & & \\
\hline \multicolumn{5}{|c|}{ Feelings about side effects (FSE) } \\
\hline Pre & $26.75 \pm 16.46(0-50)$ & $29.0 \pm 22.99(0-75)$ & 0.25 & .79 \\
\hline Post & $59.62 \pm 24.06(25-100)$ & $13.62 \pm 13.22(0-50)$ & 8.04 & $<.001$ \\
\hline Test of sig. & $\mathrm{W}=6.02$ & $\mathrm{~W}=4.59$ & & \\
\hline$p$ value & $<.001$ & $<.001$ & & \\
\hline \multicolumn{5}{|c|}{ Satisfaction with therapy (SWT) } \\
\hline Pre & $29.42 \pm 17.03(0-50)$ & $32.57 \pm 23.28(0-71.43)$ & 0.30 & .75 \\
\hline Post & $62.14 \pm 23.13(25-100)$ & $17.35 \pm 16.98(0-50)$ & 7.62 & $<.001$ \\
\hline Test of sig. & $\mathrm{W}=6.08$ & $\mathrm{~W}=5.32$ & & \\
\hline$p$ value & $<.001$ & $<.001$ & & \\
\hline \multicolumn{5}{|l|}{ Mean total score } \\
\hline Pre & $27.35 \pm 15.51(0-50)$ & $30.19 \pm 22.09(0-71.43)$ & 0.56 & .57 \\
\hline Post & $60.02 \pm 23.55(25-100)$ & $14.72 \pm 13.10(0-50)$ & 7.92 & $<.001$ \\
\hline Test of sig. & $\mathrm{W}=5.98$ & $\mathrm{~W}=5.15$ & & \\
\hline$p$ value & $<.001$ & $<.001$ & & \\
\hline
\end{tabular}

Table 4. Total score of cancer copingof the subjects

\begin{tabular}{|c|c|c|c|c|}
\hline \multirow{3}{*}{ Total score of cancer coping } & \multicolumn{2}{|c|}{ Studied groups } & \multirow{3}{*}{ Test of sig. } & \multirow{3}{*}{$p$ value } \\
\hline & \multirow{2}{*}{$\begin{array}{l}\text { Group I (Study) }(\mathbf{n}=50) \\
\text { Mean } \pm \text { SD }\end{array}$} & \multirow{2}{*}{$\begin{array}{l}\text { Group II (Control) }(\mathbf{n}=\mathbf{5 0}) \\
\text { Mean } \pm \text { SD }\end{array}$} & & \\
\hline & & & & \\
\hline \multicolumn{5}{|l|}{ Total score of cancer coping } \\
\hline Pre & $35.64 \pm 10.10$ & $38.28 \pm 11.10$ & $\mathrm{~T}=1.24$ & .21 \\
\hline Post & $58.20 \pm 13.58$ & $29.06 \pm 6.54$ & $\mathrm{~T}=13.66$ & $<.001$ \\
\hline Paired $t$ test & 19.91 & 8.45 & & \\
\hline$p$ value & $<.001$ & .001 & & \\
\hline
\end{tabular}


Table 5. Correlation between total score of patients' knowledge (baseline) \& total score of cancer coping (baseline) among subjects

\begin{tabular}{|c|c|c|c|c|}
\hline \multirow{3}{*}{ Variable } & \multicolumn{4}{|c|}{ Total score of patients knowledge } \\
\hline & \multicolumn{2}{|c|}{$\begin{array}{l}\text { Group I (Study) } \\
(n=50)\end{array}$} & \multicolumn{2}{|c|}{$\begin{array}{l}\text { Group II (Control) } \\
(n=50)\end{array}$} \\
\hline & $\mathbf{r}$ & $p$ value & $\mathbf{r}$ & $p$ value \\
\hline Total score of cancer coping & 0.68 & $<.001$ & 0.41 & .003 \\
\hline
\end{tabular}

Table 6. Correlation between total score of patients' knowledge (baseline) \& mean score of Attributes of cancer therapy satisfaction (baseline) among subjects

\begin{tabular}{|c|c|c|c|c|}
\hline \multirow{3}{*}{ Variable } & \multicolumn{4}{|c|}{ Total score of patients knowledge } \\
\hline & \multicolumn{2}{|c|}{$\begin{array}{l}\text { Group I (Study) } \\
(n=50)\end{array}$} & \multicolumn{2}{|c|}{$\begin{array}{l}\text { Group II (Control) } \\
(\mathrm{n}=\mathbf{5 0})\end{array}$} \\
\hline & $\mathbf{r}$ & $p$ value & $\mathbf{r}$ & $p$ value \\
\hline $\begin{array}{l}\text { Mean score of attributes of } \\
\text { cancer therapy satisfaction }\end{array}$ & 0.46 & .001 & 0.44 & .002 \\
\hline
\end{tabular}

Table 7. Correlation between total score of patients' cancer coping (baseline) \& mean score of attributes of cancer therapy satisfaction (baseline) among subjects

\begin{tabular}{llllll}
\hline \multirow{2}{*}{ Variable } & \multicolumn{3}{l}{ Total score of patients cancer coping } \\
\cline { 2 - 3 } & $\begin{array}{l}\text { Group I (Study) } \\
(\mathbf{n}=\mathbf{5 0})\end{array}$ & \multicolumn{2}{l}{$\begin{array}{l}\text { Group II (Control) } \\
(\mathbf{n}=\mathbf{5 0})\end{array}$} \\
\cline { 2 - 3 } & $\mathbf{r}$ & $\boldsymbol{p}$ value & & $\mathbf{p}$ value \\
\hline $\begin{array}{l}\text { Mean score of attributes of } \\
\text { cancer therapy satisfaction }\end{array}$ & $0.47 \quad<.001$ & & 0.46 & .001 \\
\hline
\end{tabular}

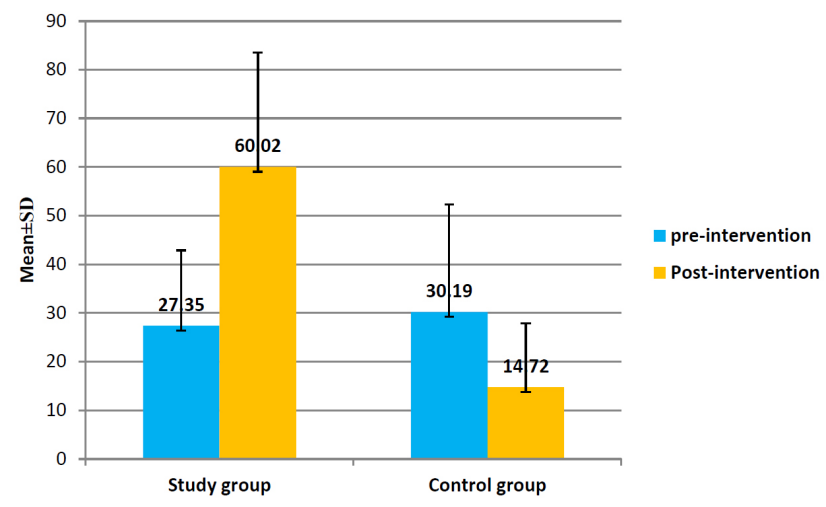

Figure 1. Attributes of cancer therapy satisfaction of the studied groups

\section{Discussion}

Cancer patients undergo some form of treatment including receiving chemotherapy as a component of their treatment. Hence these patients precise desire for information to prepare themselves for treatment mostly in relation coping with cancer treatment and satisfaction about side effect of treatment.

Concerning to sociodemographic characteristics the present study showed that more than half of study group and control 102 group were male and most of them had moderate education. Also all study samples were married and most of them suffering from gastrointestinal cancer. Moreover the mean age of study and control group were fifty three and with no statistical significant differences between both groups regarding sociodemographic characteristics. These results approximately agreement with Chan et al. ${ }^{[16]}$ that assess emerging role of pharmacist in prechemotherapy counseling-amongbreast-cancer-patients. His result showed that all sample was female although males were not excluded. Approximately fifty percentages of the patients were aged between fifty to sixty years old. Most of subjects had only secondary education. This contradiction might be attributed to application of the current research to all types of cancer. At the same line Elshamy ${ }^{[5]}$ found that there were no significant differences at baseline between groups for any of the demographic and clinical characteristics.

The existing study revealed that the majority of studied groups had poor knowledge before intervention. This result was in line with Tian et al. ${ }^{[17]}$ stated many patients with lung cancer have little knowledge about cancer treatment and rehabilitation. Moreover in present study more than two thirds of study group had good knowledge about chemotherapy post intervention; with statistical significant differences between both groups regarding chemotherapy knowledge total score post intervention. These results in agreement with Kumar and Shubham ${ }^{[18]}$ who assessed knowledge and Screening for Cervical Cancer among Women he found that majority of women had poor knowledge before intervention. In line with the present results Waller et al. ${ }^{[3]}$ indicated that providing preparatory information can improve knowledge in cancer patients undergoing chemotherapy. Furthermore, Dang et al. ${ }^{[19]}$ recommended pre-chemotherapy counseling to improve patient knowledge and understanding of the chemotherapy regimen received.

Concerning to total score of cancer therapy satisfaction pre and post intervention the current study revealed more than half of study group improved satisfaction post intervention that compared to study and control group pre intervention. Furthermore improved total satisfaction score among study group post intervention compared to control group and statistically significant differences between both groups regarding to total score of cancer therapy satisfaction post intervention. These results agreement with Garcia ${ }^{[20]}$ who found that $\mathrm{Pa}$ tients indicated on the satisfaction survey truly enjoyed the education and found it helpful. Besides a majority of participants agreed or strongly agreed that they were satisfied with the educational intervention. Elshamy ${ }^{[5]}$ added that there were statistically significant differences between both groups regarding program satisfaction. Furthermore, Waller et al. ${ }^{[3]}$ 
stated patients who received preparatory chemotherapy information across multiple sessions reported high level of satisfaction. From our point of view this might be attributed to positive effect of prechemotherapy education on patients' knowledge which later improves their satisfaction.

Regarding to total score of cancer coping of the studied groups the existing study revealed that more than half of study group had an improvement in cancer coping post intervention as compared to control group pre and post intervention. These results agreement with Monkyaw ${ }^{[21]}$ found that the education prechemotherapy was effective and minimize treatments side effects and supports the use of effective coping mechanism. Furthermore, Beszczynski ${ }^{[10]}$ indicated verbal discussions and providing printed information help patients to cope and manage their treatment.

At the same line Silva et al. ${ }^{[9]}$ who studied anxiety and coping in women with breast cancer in chemotherapy revealed that the problem-focused coping may be a strong determinant of adaptation to breast cancer. It is of paramount importance that nurses who experience the care of women undergoing chemotherapy should be aware of the coping strategies used, that help them cope more effectively with the process experienced by them. Thus, the results of this study were of great relevance to assist nurses to provide adequate care to women with breast cancer who undergoing chemotherapy.

The existing study illustrated that there were relationship between total score of patients' knowledge and total score of cancer coping. Therefore patients' knowledge among studied group affected by total score of cancer coping and improve coping. Moreover there were statistically significant differences between total score of patients' knowledge and total score of cancer coping. These results supported by Elshamy ${ }^{[5]}$ who found that information and knowledge about what to expect may lead to improved coping strategies. Therefore knowledge intervention described in this paper can be adapted to meet the education needs of almost newly diagnosed patient with cancer's patient who will begin chemotherapy. Similarly Prouse ${ }^{[22]}$ and Stephenson ${ }^{[23]}$ supported these results by describing the typical routine during chemotherapy treatment and exposing patients to the concentration area before treatment reduces uncertainty and improve coping. From our point of view prechemotherapy education allows patients to redirect unpleasant emotional responses toward functional responses. Functional responses could be improve coping, decrease side effect and increase patient involvement in his care.

The current study showed that there were relationship between total score of patients' knowledge (baseline) and mean score of cancer therapy satisfaction (baseline) among studied groups. Therefore patients' knowledge among studied group affected by cancer therapy satisfaction, highly statistically significant differences between total score of patients' knowledge (baseline) and mean score of cancer therapy satisfaction. These results agreed with Elshamy ${ }^{[5]}$ who found that the intervention group patients were markedly more satisfied with the information received than patients in the control group and reported significantly more satisfied with overall care. Furthermore, Garcia ${ }^{[20]}$ inadequate patient preparation before chemotherapy can lead to poor psychosocial outcomes and dissatisfaction with care thus education performed by nurses before the first chemotherapy infusion in a quiet environment is most effective.

The present study showed that relationship between total score of patients' cancer coping (baseline) and mean score of cancer therapy satisfaction (baseline) among studied groups, highly statistically significant differences between total score of patients' knowledge (baseline) and mean score of cancer therapy satisfaction. These results agreed with Anne et al. ${ }^{[2]}$ who studied The Patient-healthcare Professional relationship and communication in the oncology outpatient setting. They stated that the relationship with the nurses was an important role for coping with the disease and influenced general satisfaction. Therefore the patients' ability to cope with cancer has an impact on satisfaction of care. From our points of view all patients with cancer in any setting or age need preparatory knowledge and education to know how to cope and satisfy with new therapy and its complications.

\section{Conclusion}

Based on the results of the present study, it can be concluded that prechemotherapy preparations to newly diagnosed patients with cancer can improve their knowledge, satisfaction and coping with chemotherapy.

\section{Recommendation}

- Prechemotherapy education should be considered a part of routine nursing care performed for all newly diagnosed patients with cancer who would receive chemotherapy for first time.

- A written updated protocol of prechemotherapy preparation supplemented by an illustrative booklet should be available for all newly diagnosed patients with cancer who would receive chemotherapy for first time.

- Replication of the study with large probability sample to permit more generalization of the study results.

\section{CONFLiCTS OF INTEREST Disclosure}

The authors declare they have no conflicts of interest. 


\section{REFERENCES}

[1] Ganz P, Yip C, Gralow J, et al. Supportive care after curative treatment for breast cancer (survivorship care): Resource allocations in low- and middle-income countries. A Breast Health Global Initiative 2013 Consensus Statement. 2013; 22: 606-15.

[2] Rust C, Davis C. Health literacy and medication adherence in underserved African-american breast cancer survivors: a qualitative study. Social Work in Health Care. 2011; 50: 739-61. PMid:21985113. https://doi.org/10.1080/00981389.2011.585703

[3] Waller A, Forshaw K, Bryant J, et al. Interventions for preparing patients for chemotherapy and radiotherapy: a systematic review. Supportive Care in Cancer. 2014; 22(8): 2297-308. PMid:24906837. https://doi.org/10.1007/s00520-014-2303-3

[4] Mehta R, Roth A. Psychiatric Considerations in the Oncology Setting. CA Cancer J Clin. 2015; 65: 300-14. PMid:26012508. https://doi.org/10.3322/caac. 21285

[5] Elshamy K. Effect of Implementing a Prechemotherapy Education Programme on Psychological Distress, Quality of Life, and Satisfaction of Egyptian Women Newly Diagnosed with Breast Cancer. Arch Can Res. 2016; 4: 2. https://doi.org/10.21767/2254-6081. 100076

[6] Al-Quteimat O, Amer A. Evidence-based pharmaceutical care: The next chapter in pharmacy practice. Saudi Pharm J. 2016; 24: 447-51. PMid:27330375. https ://doi.org/10.1016/j.jsps.2014.07 .010

[7] Tuffaha H, Abdelhadi O, Omar S. Clinical pharmacy services in the outpatient pediatric oncology clinics at a comprehensive cancer center. Int J Clin Pharm. 2012; 34: 27-31. PMid:22207272. https://doi.org/10.1007/s11096-011-9600-4

[8] National Comprehensive Cancer Network. NCCN Clinical Guidelines in Oncology. Distress Management Version 2. July 8, 2014.

[9] Silva A, Zandonade E, Helena M. Anxiety and coping in women with breast cancer in chemotherapy Rev. Latino-Am. Enfermagem. 2017; 25: 2891. PMid:28591299. https ://doi.org/10.1590/1518-8 345.1722 .2891

[10] Beszczynski J. Improving Adult Oncology Patient Knowledge: Creating an Educational Program Using Multiple Methods of Teaching. Available from: http://webcache.g oogleusercontent . com/search?q=cache: $\mathrm{PjOMbj-j0WAJ} \mathrm{:}$ Www. pennstatehershey.org/documents/1699942/1089554 3/GN2015July_ImprovingAdultOncology/00f5d10e-607 $2-41 b 0-a 99 b-d 2177836 f 65 c+\& c d=3 \& h l=e n \& c t=c l n k \& g l=h k$ Retrived on 20-11-2018

[11] National Cancer Registry Programme. Available from: https://www . esmo.org/content/search?SearchText =oncology+News\&SearchButton=. Retrieved on: 20-5-2015.

[12] Statistical records of Oncology, Menoufia University Hospital, 2015.

[13] Tannock IF, Hill RP, Bristow RG. The basic science of oncology, 4th ed, New York, Mc Graw Hill. 2005.
[14] Abetz L, Coombs JH, Keininger DL, et al. Development of the Cancer Therapy Satisfaction Questionnaire item generation and content validity testing item generation and content validity testing Value Health. 2005; 8(Suppl. 1): S41-53. PMid:16336488. https ://doi.org/10.1111/j.1524-4733.2005.00073.x

[15] Greer S, Moorey S. Adjuvant Psychological Therapy for patients with cancer: a prospective randomised trial. Br Med J. 1992; 304: 675-680. https://doi.org/10.1136/bmj .304.6828.675

[16] Dang CC, Amiruddin M, Lai SS, et al. An emerging role of pharmacist in pre-chemotherapy counseling among breast cancer patients. Indian Journal of Pharmaceutical Sciences. 2017; 79(2): 294-302. https://doi.org/10.4172/pharmaceutical -sciences. 1000228

[17] Tian J, Jia L, Cheng Z. Relationships between patient knowledge and the severity of side effects, daily nutrient intake, psychological status, and performance status in lung cancer patients. Curr Oncol. 2015; 22(4): e254-e258. PMid:26300675. https ://doi.org/10.3747/ co. 22.2366

[18] Kumar H, Shubham T. A Study on Knowledge and Screening for Cervical Cancer among Women in Mangalore City, Noble. Ann Med Health Sci Res. 2014 Sep-Oct; 4(5): 751-6. PMid:25328788. https ://doi .org/10.4103/2141-9248.141547

[19] Dang M, Amiruddin S, Lai C, et al. An Emerging Role of Pharmacist in Pre-chemotherapy Counseling Among Breast Cancer Patients. Indian Journal of Pharmaceutical Sciences. 2017; 79(2): 294-302. https://doi.org/10.4172/pharmaceutical -sciences. 1000228

[20] Garcia S. The Effect of Patient Education on Anxiety Levels in Patients Receiving chemotherapy for the First Time. Evidence based practice project report, submitted to the college of Nursing of Valparaiso University, Indiana, in partial fulfillment of the requirement for the degree of doctor of nursing practice. 2014.

[21] Monkyaw T. Quality of life and coping mechanism among patients with cancer. Medical research and ethics committee of the faculty of medicine and health sciences. 2012.

[22] Prouse J. The impact of methods of information on chemotherapyrelated side effects. Clinical Journal of Oncology Nursing. 2010; 14: 206-11. PMid:20350894. https : //doi .org/10.1188/10. CJON. 206-211

[23] Stephenson P. Before the teaching begins: Managing patient anxiety prior to providing education. Clinical Journal of Oncology Nursing. 2006; 10: 241-5. PMid:16708707. https://doi.org/10.1188/ 06. CJON . 241-245

[24] Anne P, Kirsten A, Nielsen D, et al. The Patient-Healthcare Professional Relationship and Communication in the Oncology Outpatient Setting: A Systematic Review. Cancer Nursing. 2018; 41(5): E11E22. PMid:28753191. https://doi.org/10.1097/NCC.000000 0000000533 